zeros of the circular functions. There are a short paragraph on the quadrature problem, and an account of the calculation of $\pi$, mentioning the infinite products of Vieta and Wallis, the Gregory series, the Machin formula and the Shanks determination of 707 decimal places. Ferguson's discovery of an error in Shanks's figures is not mentioned, but this does not affect the 40 decimal places given; machine calculations to 100,000 decimal places have come too recently to be referred to.

The printing is very good, even in small-type symbolic work, and there are few misprints, though some proper names are mis-spelt. It is difficult to name any topic which is not dealt with, but there is a noticeable variation in scale, both in the main text and in the bibliographies, a defect which could perhaps scarcely have been avoided by the most careful editorial supervision in such an enterprise as this, wherein more than 120 mathematicians have collaborated. It is indeed a solid German monument to mathematical scholarship. T. A. A. BRoADBENT

\section{PROPAGATION THEORY}

\section{Electromagnetic Waves}

Proceedings of a Symposium conducted by the Mathematics Research Center, United States Army, at the University of Wisconsin, Madison, April 10-12, 1961. Edited by Rudolph E. Langer. Pp. xii +396. (Madison: University of Wisconsin Press, 1962.) 6 dollars.

T HIS volume is the record of a symposium conducted by the Mathematics Research Center, United States Army, in the University of Wisconsin, during April 10-12, 1961.

The title of the work suggests probably a greater gonerality in the contents than is intended, for the matter contained relates almost exclusively to the propagation of waves in free space and to the attendant problems of diffraction, scattering and aerial theory. Some sixteen papers by a selection of eminent authorities are included although none of the discussions which took place during the conference is reported.

Although the appeal of the book will be mainly to the mathematical specialist in the field defined, a number of the constituent papers are in the nature of reviews and may well serve as introduction to present-day thinking for a rather wider audience. For example, the paper by M. Kline on "Electromagnetic Theory and Geometrical Optics" includes a useful review of the historical aspects of the two approaches, in addition to delineating the fields of application of either technique, and discussing some of the remaining "open problems". In a similar manner the longest of the papers included, "The Propagation of Electromagnetic Waves along tho Earth's Surface", by J. R. Wait, while mainly presenting an up-to-date account of the author's own investigations of the subject, implicitly summarizes much of the earlier work in this field.

The greatest number of papers on any one specific topic relate to diffraction theory. Of these the essentially 'pure' mathematician's approach is represented by "The Mathematical Foundations of Dif. fraction Theory" by C. H. Willcox, in which the general diffraction problem is formulated in precise mathematical terms together with appropriate exist- ence and uniqueness theorems, and further theorems governing the functional properties of the solution. The use of "Abstract Operator Methods in Electromagnetic Diffraction" is discussed in a paper by Marcuvitz, who points out that despite the extensive use of this approach in quantum mechunical investiga. tions the technique has been but little utilized in diffraction theory. Further papers in this field include an extensive discussion of "A Mathematical Model for Diffraction by Convex Surfaces", and a general treatment of diffraction by polygonal cylinders.

Several of the papers refer to aerial calculations, of particular interest being a discussion of "The Pulse Solution Connected with the Sommerfeld Problem for a Dipole in the Interface between Two Dielectrics" by H. Bremmer, and a treatment of "Dipoles in Dissipative Media" by R. W. P. King. This latter treatment could relate, for example, to such cases as rudiation from a submarine aerial or from a rocket antenna probe in an ionized region or plasma sheath.

A useful addition to the analytical techniques of scattering theory is provided by "The Quasi Static Radar Cross Sections of Complex Bodies of Radiation" by K. M. Siegel, which extends the author's earlier methods to obtain higher order solutions than proviously.

Mention should also be made of a short, but interesting, paper by G. Goubau entitled "Some Characteristics of Electromagnetic Wave Beams", which makes some pertinent comments on the currently interesting subject of 'coherent-' and 'incoherent-' optics.

In summary, this collection of papers is full of stimulating, if esoteric, interest, and is certainly deserving of a place in any library serving the needs of those concerned with the theory of aerials and wave propagation.

G. D. SIMs

\section{MEDICINAL AND POISONOUS PLANTS}

Piante Medicinali

Chimica Formacologia e Terapia, Vol. 1. Da Dr. Benigni, Dr. C. Capra e Dr. P. E. Cattorini. Pp. vii +730 . (Milano: Inverno and Della Beffa, 1962.) 8,000 lire.

\section{The Medicinal and Poisonous Plants of Southern and} Eastern Africa

Being an Account of Their Medicinal and Other Uses, Chemical Composition, Pharmacological Effects and Toxicology in Man and Animal. By Prof. John Mitchell Watt and Dr. Maria Gerdina Breyer-Brandwijk. Second edition. Pp. xii +1457 . (Edinburgh and London: E. and S. Livingstone, Ltd., 1962.) $252 s$.

7 WO interesting new books on medicinal or poisonous plants have recently appeared, one in Italy and the other in South Africa.

The Italian book, Piante Medicinali, is the first volume of a new two-volume work and deals with some 144 species arranged according to their common Italian names and covering the letters $A$ to $H$. The second volume (due to appear this year) will deal with another 120 species under the letters $I$ to $Z$. Each species is dealt with in similar fashion, the space devoted to each depending on its importance medicinally. There are notes or information on etymology 